Arq. Bras. Med. Vet. Zootec., v.68, n.2, p.321-326, 2016

\title{
Expressão gênica em ovócitos suínos de diferentes classificações morfológicas
}

[Gene expression in swine oocytes in different morphological classifications]

\author{
F.A.S.A.M. Oliveira ${ }^{1}$, D.M. Paixão ${ }^{1}$, L.S. Amorim ${ }^{1}$, D.B. Pereira ${ }^{2}$, \\ S.E.F. Guimarães ${ }^{3}$, J.D. Guimarães ${ }^{3}$ \\ ${ }^{1}$ Aluno de pós-graduação - Universidade Federal de Viçosa - Viçosa, MG \\ ${ }^{2}$ Instituto de Zootecnia - Estação Experimental de Nova Odessa, SP \\ ${ }^{3}$ Universidade Federal de Viçosa - Viçosa, MG
}

\begin{abstract}
RESUMO
A produção in vitro de embriões suínos tem alcançado resultados insatisfatórios: ovócitos maturados in vivo produzem uma porcentagem maior de embriões em relação aos maturados in vitro. O sucesso da maturação in vitro está diretamente relacionado com a competência ovocitária. Somente ovócitos competentes são capazes de serem fecundados e terem desenvolvimento embrionário normal. A competência ovocitária pode ser avaliada por vários parâmetros. Recentemente têm sido utilizados como parâmetro os estudos da expressão de genes associados com a competência. O presente trabalho teve por objetivo avaliar diferenças na expressão dos genes BMP15, RYBP, MATER e ZAR1 em ovócitos imaturos de diferentes classes morfológicas, sendo elas: 1, 2, 3 e 4, com a finalidade de proporcionar importantes marcadores moleculares relacionados com a capacidade ovocitária. O RNA total dos ovócitos foi extraído e utilizado como molde para a síntese da primeira fita de cDNA. Os resultados da expressão gênica foram analisados utilizando-se modelo misto, considerando os dados de expressão gênica variável dependente e as classes ovocitárias variáveis independentes. Os genes BMP15, ZAR1 e RYBP apresentaram expressão semelhante nas classes ovocitárias 1, 2 e 3; somente a categoria 4 diferiu na expressão desses genes $(\mathrm{P}<0,05)$. $\mathrm{O}$ gene MATER foi expresso de forma semelhante em todas as classes ovocitárias estudadas $(\mathrm{P}>0,05)$. A técnica de RT-qPCR foi eficiente para detecção desses transcritos em ovócitos de diferentes classes. No entanto, para melhor entendimento do envolvimento desses transcritos na aquisição da competência ovocitária, são necessários mais estudos avaliando ovócitos de diferentes classes morfológicas, em diferentes fases de desenvolvimento, e implicação de outros genes envolvidos com a competência ovocitária.
\end{abstract}

Palavras-chave: suíno, competência de desenvolvimento, complexo cumulus-oophorus maturação citoplasmática, maturação nuclear

\begin{abstract}
The in vitro production of pig embryos has achieved unsatisfactory results; in vivo matured oocytes produce a higher percentage of embryos compared to in vitro maturation. The success of in vitro maturation is directly related to oocyte competence. Only competent oocytes are capable of being fertilized and have normal embryonic development. The oocyte competence can be assessed using several parameters. Recently these parameters have been used for gene expression studies associated with competence. This work aimed to evaluate differences in gene expression BMP15, RYBP, MATER, ZAR1 as endogenous control and the constitutive gene GAPDH in immature oocytes of different morphological classes which are: 1, 2, 3 and 4, in order to provide significant molecular markers linked to the ability of development. Oocytes Total RNA was extracted and used as a template for synthesis of the first cDNA strand. The results of gene expression were analyzed using a mixed model, considering the dependent gene expression data and independent ovocitary variable classes. The genes BMP15, RYBP ZAR1 and
\end{abstract}

Recebido em 2 de setembro de 2014

Aceito em 21 de setembro de 2015

E-mail: flaviaalvimvet@hotmail.com 
showed similar ovocitary expression in classes 1, 2 and 3 differ only in category 4 in their expression $(P<0.05)$. The MATER gene was similarly expressed in all ovocitary classes studied $(P>0.05)$. The RTQ$P C R$ technique was effective for detection of these transcripts in oocytes from different classes. However, for better understanding of the involvement of these transcripts in the acquisition of oocyte competence more studies are needed to evaluate different morphological classes of oocytes at different stages of development and the implication of other genes involved in oocyte competence.

Keywords: pigs, developmental competence, cumulus-oophorus complex, citoplasmic maturation, nuclear maturation

\section{INTRODUÇ̃̃O}

A produção in vitro de embriões (PIV) é uma biotécnica de reprodução assistida que permite explorar cada vez mais o potencial reprodutivo das fêmeas, sendo utilizada como opção para acelerar a produção de animais geneticamente superiores. Estudos em suínos, considerando as semelhanças biológicas que partilham com os seres humanos, fornecem informações importantes para aprimorar a produção in vivo, benefícios correlacionados com células e órgãos para xenotransplantes, bem como animal transgênico para produzir proteínas específicas (Lunney, 2007). Porém, o uso dessa técnica ainda é limitado, devido à baixa proporção de blastocistos viáveis (Yoshioka et al., 2012). A maioria das mortes pré-implantação de embriões ainda não está bem elucidada (Warner et al., 1998). Entretanto, há evidências indicando que a qualidade intrínseca do ovócito é o principal fator que determina se um embrião terá habilidade de se desenvolver adequadamente (Wang e Sun, 2007). A qualidade do ovócito está ligada aos processos de maturação nuclear e de maturação citoplasmática. A maturação nuclear envolve quebra da vesícula germinativa, desaparecimento do nucléolo, condensação da cromatina, extrusão do primeiro corpúsculo polar e formação do segundo fuso meiótico (Meinecke et al., 2001). Esta é progressivamente adquirida durante as fases finais da foliculogênese, que ocorre logo após o pico de LH in vivo, e in vitro acontece espontaneamente quando os ovócitos são removidos dos folículos (Lonergan et al., 2003). A maturação citoplasmática envolve síntese de proteínas (Sirard et al., 1998), redistribuição das organelas intracelulares (Stojkovic et al., 2001) e maturação dos mecanismos de liberação do $\mathrm{Ca}^{2+}$ (Wang et al., 2003). Atualmente, a seleção de ovócitos de melhor qualidade para utilização na PIV baseiase nos critérios morfológicos (Stojkovic et al., 2001). No entanto, os atributos morfológicos, associados com a qualidade do ovócito, têm alcançado sucesso limitado. $\mathrm{Na}$ tentativa de realizar uma seleção mais precisa e que realmente reflita a competência dos ovócitos utilizados, têm sido pesquisados outros métodos, tais como tamanho do folículo, coloração com azul cresil brilhante (ACB), momento da clivagem e idade da doadora, juntamente com a avaliação morfológica (Wu et al., 2007). Estudos recentes têm sugerido que as análises celulares e moleculares de ovócitos podem fornecer índices mais precisos para a definição de critérios mais objetivos de sua qualidade. A maioria dessas abordagens não pode ser diretamente aplicada para a seleção dos ovócitos, porque a sua aplicação não preserva a viabilidade celular, mas tem o potencial para estabelecer padrões celulares para a obtenção de ovócitos competentes in vitro ou in vivo, o que promove uma seleção mais rigorosa, melhorando os resultados de produção e a qualidade dos embriões obtidos por técnicas de reprodução assistida (Coticchio et al., 2004). Assim, este trabalho teve como objetivo identificar genes que estão envolvidos com a competência ovocitária, tais como o BMP15 (Zhu et al., 2008), o RYBP (Dode et al., 2006), o MATER e o ZAR1, em ovócitos de diferentes graus de qualidade, classificados pela morfologia.

\section{MATERIAL E MÉTODOS}

No presente estudo, foram utilizados ovócitos suínos de fêmeas da linhagem comercial (Landrace $\mathrm{x}$ Large White $\mathrm{x}$ Pietran), média de 200 dias de idade e peso médio de $150,0 \mathrm{~kg}$, pertencentes à Granja de Melhoramento Genético de Suínos da Universidade Federal de Viçosa, MG, destinadas ao abate em frigorífico e comercializadas para consumo humano (procedimento aprovado pela Comissão de Ética da UFV, protocolo número 36/2012). 
Os animais utilizados encontravam-se, na ocasião da coleta dos ovócitos, no período de diestro, seis dias após a inseminação artificial. Os animais não foram submetidos a nenhum protocolo hormonal para estimular crescimento folicular. $\mathrm{O}$ abate foi feito pelo método de atordoamento elétrico e sangria; imediatamente após, os ovários foram coletados e mantidos em solução de $\mathrm{PBS}$ a $39^{\circ} \mathrm{C}$, até o momento da aspiração. Os complexos do cumulus-oophorus (CCOs) foram coletados por aspiração folicular, utilizando-se seringas de $10 \mathrm{~mL}$ acopladas com agulhas 18G. Os CCOs foram aspirados de folículos de 3-8mm. Após aspirados, foram selecionados de acordo com a morfologia do CCOs, utilizando-se a classificação proposta por Stojkovic et al. (2001) na escala de 1 a 4 . Os ovócitos de diferentes classes morfológicas foram preservados em microgotas de PBS (solução de fosfato tamponada, Nutricell, Brasil) e PVA (álcool polivinílico; Sigma Chemical Co., St. Louis, MO, USA) $0,01 \%$, em tubos criogênicos devidamente identificados, os quais foram acondicionados em nitrogênio líquido para posterior extração de RNA. Foram utilizados 10 ovócitos de cada classe morfológica, com três repetições para cada classe, totalizando 30 ovócitos por classe morfológica e duas repetições biológicas para cada amostra. Os genes selecionados para o estudo estão relacionados aos processos de maturação nuclear e citoplasmática ovocitária, sendo eles: MATER, ZAR1, BMP15 e RYBP; o gene GAPDH foi usado como controle endógeno. Os primers utilizados para amplificação dos fragmentos dos genes, cujos produtos participam do processo de maturação nuclear e do controle endógeno, foram desenhados por meio do programa Primer Blast (http://www.ncbi.nlm.nih.gov/tools/primerblast/), a partir de sequências de nucleotídeos obtidas do banco de dados do GeneBank (htpp://www.ncbi.nlm.nih.gov). As análises de RT-qPCR foram realizadas nas dependências do LABTEC - Laboratório de Biotecnologia Animal do Departamento de Zootecnia da Universidade Federal de Viçosa. As amostras de ovócitos imaturos foram descongeladas, e os COCs, desnudados com hialuronidase a $0,1 \%$ (Sigma) e sucessivas pipetagens, foram posteriormente lavados em quatro gotas de PBS e transferidos para microtubos para extração do RNA. Foi utilizado o RNeasy Micro Kit (Qiagen, Valencia, CA, USA), conforme as especificações dos fabricantes. Em seguida, foram processados para análise em PCR em tempo real para comparação do padrão de expressão gênica. A eficiência de amplificação de cada gene foi calculada por meio da construção de uma curva de diluição em série de cDNA nas concentrações de 25,75 e $225 \mathrm{ng}$ por reação. As reações foram consideradas eficientes quando a eficiência de amplificação do gene alvo e a do gene referência foram aproximadamente iguais, com tolerância de $10 \%$ de variação em relação ao controle endógeno, como descrito por Livak e Schmittgen (2001). Com base nos dados obtidos, um gráfico de $\mathrm{Ct}$ (threshold cycle) versus o $\log 10 \mathrm{da}$ quantidade de cDNA utilizada na reação foi produzido. Foi utilizada a regressão linear para determinação do coeficiente angular da reta a fim de determinar a eficiência de amplificação, de acordo com a equação desenvolvida por Pfaffl (2001). A diluição de cDNA e a concentração de primer foram escolhidas após verificada a eficiência para cada gene alvo e o controle endógeno, considerando as que apresentaram maior eficiência para preparar as reações de quantificação relativa. As reações foram efetuadas em termociclador ABI Prism 7300 Sequence Detection Systems (Applied Biosystems, Foster City, CA, USA), utilizandose GoTaq ${ }^{\circledR}$ qPCR Master Mix (Promega Corporation, Madison, USA), de acordo com as recomendações do fabricante. As condições de amplificação para todos os sistemas foram: $95^{\circ} \mathrm{C}$ durante dois minutos; 40 ciclos de desnaturação a $95^{\circ} \mathrm{C}$ por 15 segundos e extensão a $60^{\circ} \mathrm{C}$ durante 60 segundos. Nos testes de eficiência, ao final dos 40 ciclos de amplificação, um passo adicional com elevação gradual de temperatura de $60^{\circ} \mathrm{C}$ a $95^{\circ} \mathrm{C}$ foi utilizado para obtenção da curva de dissociação. A amplificação dos genes alvo e de referência endógena foi realizada em diferentes canaletas e em duplicatas na mesma placa de reação. Os dados obtidos na reação de qPCR foram gerados pelo equipamento na forma de valores de $\mathrm{Ct}$. Os valores médios de $\mathrm{Ct}$ foram subtraídos entre si para o cálculo de $\mathrm{Ct}(\mathrm{Ct}$ do alvo - $\mathrm{Ct}$ da referência endógena), a fím de minimizar as possíveis variações quanto à quantidade de mRNA inicial e à eficiência na transcrição reversa. A quantidade do gene alvo, normalizada para referência endógena, foi calculada pela fórmula $2^{-\Delta \mathrm{Ct}}$ (Livak $\mathrm{e}$ Schimittgen, 2001; Pfaffl, 2001). O delineamento experimental foi inteiramente ao acaso, com três repetições por tratamento (classe). Os dados de RT-qPCR foram analisados utilizando-se o 
modelo misto: $\mathrm{y}_{\mathrm{jkl}}=\mathrm{PRG}_{\mathrm{j}}+\mathrm{A}_{(\mathrm{j}) 1}+\mathrm{D}_{\mathrm{jk}}+\mathrm{e}_{\mathrm{jk} \mathrm{l}}$, em que: $\mathrm{y}_{\mathrm{jkl}}$ é a expressão mensurada do gene $\mathrm{k}$ no ovócito 1 da classe $\mathrm{j} ; P_{\mathrm{PRG}}$ é o efeito da classe $\mathrm{j}$; $\mathrm{A}_{(\mathrm{j}) 1}$ é o efeito aleatório do ovócito 1 dentro da classe $\mathrm{j}, \mathrm{A}_{(\mathrm{j}))^{\sim}} \sim \mathrm{N}\left(0, \sigma_{\mathrm{A}}^{2}\right) ; \mathrm{D}_{\mathrm{jk}}$ é o efeito aleatório amostra-específico (comum aos dois genes), $\mathrm{D}_{\mathrm{jk}}$ $\sim \mathrm{N}\left(0, \sigma^{2}\right)$; $\mathrm{e}_{\mathrm{jkl}}$ é o termo de erro aleatório, $\mathrm{e}_{\mathrm{jkl}} \sim$ $\mathrm{N}\left(0, \sigma_{\mathrm{e}}^{2}\right)$. As análises estatísticas foram realizadas utilizando-se a macro QPCR_MIXED desenvolvida em SAS (v.9.2), elaborada para gerar comandos do SAS PROC MIXED próprios para analisar dados de RT-qPCR, assumindo efeitos aleatórios independentes para gene referência e genes alvos em cada replicada biológica (Steibel et al., 2009). A significância das estimativas dos contrastes foi avaliada mediante o teste t de Student.

\section{RESULTADOS E DISCUSSÃO}

No presente trabalho, para a expressão do gene BMP15, os ovócitos de graus 1, 2 e 3 não apresentaram diferença significativa, somente ovócitos de grau 4 diferiu das classes anteriormente citadas $(\mathrm{P}<0,05)$. Esses resultados corroboram, parcialmente, estudos realizados por Galoway et al. (2000), Yan et al. (2001), Su et al. (2004), Paradis et al. (2009) e Rosseti et al. (2009), os quais avaliaram a função e importância desse transcrito para aquisição da competência ovocitária. No entanto, esses estudos utilizaram somente ovócitos de graus 1 e 2.

Em relação aos ovócitos de grau 3, não avaliados nos estudos citados, com o resultado obtido no presente estudo, pode-se sugerir que esses possuem capacidade de continuar seu desenvolvimento, baseado na função desse gene, apesar de apresentar um número reduzido de células da granulosa e de citoplasma heterogêneo. Já nos ovócitos de grau 4, era esperada a diminuição desse transcrito, considerando que sua função biológica está diretamente correlacionada com a coordenação das células granulosa e que ovócitos dessa classe morfológica apresentam total ausência dessas células. No presente estudo, a expressão relativa do gene MATER não diferiu entre as classes morfológicas $(\mathrm{P}>0,05)$. Esses resultados corroboram os de Tong et al. (2000), Pennetier et al. (2004) e Tong et al. (2004), considerando que todos os ovócitos utilizados neste estudo estavam em estágio de vesícula germinativa, momento esse em que a proteína ainda não é requerida para progressão da maturação e da ovulação. Portanto, no presente estudo, não foi possível correlacionar a expressão do gene MATER em ovócitos imaturos de diferentes classificações morfológicas. Os resultados obtidos sugerem que os transcritos estão presentes, mesmo em ovócitos incapazes de continuar o desenvolvimento (grau 4), porém, após a quebra da vesícula germinativa, momento em que a proteína é requerida, não serão capazes de serem ativados, o que corrobora resultados obtidos com estudos dos outros genes. No presente trabalho, ao se avaliarem a expressão do gene ZAR1 e o modelo de classificação morfológica, não houve diferença na expressão desse transcrito para ovócitos de graus 1,2 e $3(\mathrm{P}<0,05)$. Esses resultados são em parte semelhantes aos registrados por outros autores (Wu et al., 2003; Whitworth et al., 2005). Os estudos realizados por esses autores foram feitos utilizando-se apenas ovócitos de graus 1 e 2, portanto não é possível estabelecer uma relação com a presença desses transcritos em ovócitos de grau 3. No presente estudo, a semelhança na expressão do gene ZAR1 nessa classe pode ser explicada pelo fato de que, embora ovócitos de grau 3 não estejam competentes morfologicamente, os transcritos necessários para progressão desses ovócitos para além dos estágios embrionários estão presentes. Como essa avaliação molecular não é possível mediante o uso do modelo morfológico, este estudo sugere que a avaliação morfológica não é totalmente eficaz para selecionar ovócitos competentes, embora investigações utilizando ovócitos em outros estágios de desenvolvimento sejam necessárias. No presente estudo, ao se avaliar o gene RYBP, ovócitos de graus 1, 2 e 3 apresentaram expressão semelhante desse gene $(\mathrm{P}>0,05)$. Somente ovócitos de grau 4 diferiram das classes anteriormente citadas $(\mathrm{P}<0,05)$. Esse resultado corrobora em parte o encontrado por Vigneault et al. (2004), os quais constataram grande presença de transcritos em ovócitos em estágio de vesícula germinativa, no entanto esses autores utilizaram somente ovócitos de graus 1 e 2 . Tais resultados sugerem, em relação à função desse gene, que ovócitos de grau 3 são competentes para o desenvolvimento embrionário. 


\section{CONCLUSÃO}

Os genes BMP15, RYBP e ZAR1 foram expressos de forma semelhante em ovócitos de classificação 1, 2 e 3, sugerindo que estes são competentes para o desenvolvimento embrionário. No entanto, no presente estudo, não foi possível associar o envolvimento do gene MATER em ovócitos imaturos de diferentes categorias.

\section{AGRADECIMENTOS}

À Granja de Melhoramento Genético de Suínos da UFV, por prover as condições para a realização deste experimento.

\section{REFERÊNCIAS}

COTICCHIO, G.; SERENI, E.; SERRAO, L. et al. What criteria for the definition of oocyte quality? Ann. N. Y. Acad. Sci., v.1034, p.132-44, 2004.

DODE, M.A.N. Avanços na maturação ovocitária em bovinos. In: ENCONTRO ANUAL DA SOCIEDADE BRASILEIRA DE TECNOLOGIA DE EMBRIÕES, 21., Araxá, 2006. Anais... Araxá: SBTE; 2006. p.115-29.

GALLOWAY, S.M.; MCNATTY, K.P.; CAMBRIDGE, L.M. et al. Mutations in an oocyte-derived growth factor gene (BMP15) cause increased ovulation rate and infertility in a dosage-sensitive manner. Nat. Genet., v.25, p.279-283, 2000.

LIVAK, K. J., SCHMITTIGEN T. D. Analysis of relative gene expression data using real-time quantitative PCR and the 2 (-Delta Delta C (T) method. Methods, v.25, p.402-408, 2001.

LONERGAN, P.; RIZOS, D.; GUTIERREZADAN, A. et al. Oocyte and embryo quality: effect of origin, culture conditions and gene expression patterns. Reprod. Domest. Anim., v.38, p.259-267, 2003.

LUNNEY, J.K. Advances in swine biomedical model genomics. Int. J. Biol. Sci., v.3, p.179184, 2007.

MEINECKE, B; JANAS, U; PODHAJSKY, E. et al. Histone $\mathrm{H} 1$ and MAP kinase activities in bovine oocytes following protein synthesis inhibition. Reprod. Domest. Anim., v.36, p.183$188,2001$.
PARADIS, F.; NOVAK, S.; MURDOCH, G.K. et al. Temporal regulation of BMP2, BMP6, BMP15, GDF9, BMPR1A, BMPR1B, BMPR2 and TGFBR1 mRNA expression in the oocyte, granulosa and theca cells of developing preovulatory follicles in the pig. Reproduction, v.139, p.115-129, 2009.

PENNETIER, S.; UZBEKOVA, S.; PERREAU, C. et al. Spatio-temporal expression of the germ cell marker genes MATER, ZAR1, GDF9, BMP15, and VASA in adult bovine tissues, oocytes, and Preimplantation embryos. Biol. Reprod., v.71, p.1359-1366, 2004.

PFAFFL, M. W. A new mathematical model for relative quantification in realtime RT-PCR. Nucleic Acids Res., v.29, p.45, 2001.

ROSSETTI, R.; DI PASQUALE, E.; MAROZZI, A. et al. BMP15 mutations associated with primary ovarian insufficiency cause a defective production of bioactive protein. Hum. Mutat., v.30, p.804-810, 2009.

SAS/STAT ® 9.2 : user's guide., 2009. 2.ed. Cary, NC: SAS Institute, 2009.

SIRARD, M.A.; RICHARD, F.; MAYES, M. Controlling meiotic resumption in bovine oocytes: a review. Theriogenology. v.49. p.483497. 1998.

SIRARD, M.A.; RICHARD, F.; BLONDIN, P. et al. Contribution of the oocyte to embryo quality. Theriogenology, v.65, p.126-36, 2006.

STEIBEL, J.P.; POLETTO, R.; COUSSENS, P.M. et al. A powerful and flexible linear mixed model framework for the analysis of relative quantification RT-PCR data. Genomics, v.94, p.146-152, 2009.

STOJKOVIC, M.; MACHADO, A.S.; STOJKOVIC, P. et al. Mitochondrial distribution and adenosine triphosphate content of bovine oocytes before and after in vitro maturation: correlation with morphological criteria and developmental capacity after in vitro fertilization and culture. Biol. Reprod., v 64, p.904-909, 2001. 
SU, Y.Q.; WU, X.; BRIEN, M.J.O.; PENDOLA, F.L. et al. Synergistic roles of BMP15 and GDF9 in the development and function of the oocytecumulus cell complex in mice: genetic evidence for an oocyte-granulosa cell regulatory loop. Dev. Biol., v.276, p.64-73, 2004.

TONG, Z.B.; GOLD, L.; DE POL, A. et al. Developmental expression and subcellular localization of mouse MATER, an oocytespecific protein essential for early development. Endocrinology, v.145, p.1427-1434, 2004.

TONG, Z.B.; GOLD, L.; PFEIFER, K.E. et al. Mater, a maternal effect gene required for early embryonic development in mice. Nat. Genet., v.26, p.267-268, 2000.

VIGNEAULT, C.; MCGRAW, S.; MASSICOTTE, L. et al. Transcription factor expression patterns in bovine in vitro-derived embryos prior to maternal-zygotic transition. Biol. Reprod., v.70, p.1701-1709, 2004.

WARNER, C.M.; MC ELHINNY, A.S.; WU, L. et al. Role of the ped gene and apoptosis genes in control of preimplantation development. $J$. Assist. Reprod. Genet., v.15, p.331-337, 1998.

WANG, W.; DAY, B.N.; WU, G. How does polyspermy happen in mammalian oocytes? Microsc. Res. Techniq., v.61, p.335-341, 2003.

WANG, Q.; SUN, Q.Y. Evaluation of oocyte quality: Morphological, cellular and molecular predictors. Reprod. Fertil. Develop., v.19, p.1$12,2007$.
WHITWORTH, K.M.; AGCA, C.; KIM, J.G. et al. Transcriptional profiling of pig embryogenesis by using a $15-\mathrm{K}$ member unigene set specific for pig reproductive tissues and embryos. Biol. Reprod., v.72, p.1437-1451, 2005.

WU, X.; WANG, P.; BROWN, C.A. et al. Zygote arrest 1 (Zar1) is an evolutionarily conserved gene expressed in vertebrate ovaries. Biol. Reprod., v.69, p.861-867, 2003.

WU, Y-G.; LIU, Y.; ZHOU, P.; LAN, G-C.; HAN, D.; MIAO, D-Q.; TAN, J-H. Selection of oocytes for in vitro maturation by brilliant cresyl blue staining: a study using the mouse model. Cell Research.v.17. p. 722-731. 2007.

YAN, C.; WANG, P.; DEMAYO, J. et al. Synergistic roles of bone morphogenetic protein 15 and growth differentiation factor 9 in ovarian function. Mol. Endocrinol., v.6, p. 854-866, 2001.

YOSHIDA, M.; ISHIZAKI, Y.; KAWAGISHI, $\mathrm{K}$; et al. Effects of pig follicular fluid on maturation of pig oocytes in vitro and on their subsequent fertilizing and developmental capacity in vitro. J. Reprod. Fertil., v.95, p.481488, 1992.

YOSHIOKA, K.; NOGUCHI, M. SUZUKI, C. Production of piglets from in vitro-produced embryos following non-surgical transfer. Animal Reproduction Science. v.131. p. 23-29. 2012.

ZHU, G.; GUO, B.; PAN, D.; MU, Y.; FENG S. Expression of bone morphogenetic proteins and receptors in porcine cumulus-oocyte complexesduring in vitro maturation. Animal Reproduction Science.v.104. p.275-283, 2008. 